\title{
Flow Field of a Dual-Stream Jet with External Wedge- Shaped Deflector
}

\author{
Rebecca S. Shupe* \\ University of California, Irvine, CA 92697-3975 \\ James R. DeBonis ${ }^{\dagger}$ \\ NASA Glenn Research Center, Cleveland, OH, 44135-3127
}

The research effort is a Reynolds-Averaged Navier-Stokes (RANS) investigation that looks at the flow-field and performance of a bypass ratio 8 nozzle with an external wedgeshaped noise suppressor, simulating the exhaust of a turbofan engine at takeoff conditions. Peak turbulence was reduced by the wedge on the side opposite the deflector, and it was increased in the initial region of the jet behind the deflector. Flow-field trends agreed with the expectations based on static jet experiments. The calculated thrust loss was $1.1 \%$ at takeoff conditions.

\section{Symbols}

$\begin{array}{ll}C_{D} & =\text { discharge coefficient } \\ C_{f g} & =\text { thrust coefficient } \\ D & =\text { nozzle exit diameter } \\ F & =\text { force (thrust or drag) } \\ k & =\text { turbulent kinetic energy }=1 / 2\left(\overline{u^{\prime 2}+v^{\prime 2}+w^{\prime 2}}\right) \\ \dot{m} & =\text { mass flux } \\ \bar{u} & =\text { mean axial velocity component in jet plume } \\ u^{\prime} & =\text { RMS axial velocity component in jet plume } \\ v^{\prime} & =\text { RMS vertical velocity component in jet plume } \\ w^{\prime} & =\text { RMS horizontal velocity component in jet plume } \\ x & =\text { axial position with respect to fan exit } \\ \alpha & =\text { wedge half angle } \\ \phi & =\text { azimuth angle relative to downward vertical }\end{array}$



\section{Introduction}

symmetric jets are a viable means for directional noise suppression from separate-flow aircraft engines ${ }^{1-2}$. "Offset-stream" methods, tested extensively both at the University of California, Irvine and at NASA Glenn Research Center have demonstrated potential for application on commercial and military aircraft ${ }^{1-11}$. In the case of

*Graduate Student Researcher, AIAA Member.

${ }^{\dagger}$ Aerospace Engineer, Propulsion Systems Division, 21000 Brookpark Road, M.S. 5-12, Cleveland, OH 44135-3127, AIAA Associate Fellow. 
the external wedge-shaped deflector, asymmetry is created in the jet by causing the paths of the fluid elements near the top of the bypass duct to diverge toward the sides and beneath the jet. Regions of intense turbulent eddy formation are targeted by this method, and a thickened low-speed region results in reduced radial velocity gradients and peak turbulent kinetic energy levels in the lower hemi-cylinder of the jet ${ }^{3}$. Acoustic emissions over a range of azimuthal angles toward the ground are reduced ${ }^{2}$.

This research effort continues a series of RANS investigations at the NASA John H. Glenn Research Center, that focus on the "offset-stream" methods for jet noise suppression ${ }^{21-25}$. In the current work, the emphasis is on the asymmetric jet resulting from an external wedge-shaped deflector placed in the bypass stream of a nozzle simulating takeoff conditions. The wedge-type deflector is unique because in a nozzle with convergent exit geometry it reduces noise emissions across the entire spectrum of frequencies, without crossover at high polar angles ${ }^{6}$. Particular attention is given to the external wedge because minimal change in the mass flow rate in the fan stream is effected upon its presence. The nozzle performance was evaluated using the discharge coefficient because it takes into account the change in mass flow rate on the total thrust.

\section{Nozzle Configurations}

\section{A. Baseline Nozzle}

The nozzle used in the Aeroacoustic Propulsion Laboratory at NASA GRC has a bypass-ratio of 8 at typical turbofan exhaust conditions. It has convergent exit flow lines, and it is also used in the experimental studies ${ }^{10-12}$. The exit conditions are listed in Table 1, and the nozzle and wedge coordinates are plotted in Fig. 3.

\section{B. External Wedge}

The height of the external wedge configuration is two times the annular gap width. In forward flight, the tall wedge is not an optimal configuration based on the expected aerodynamic performance. The cross-section of the wedge is constantly diverging, with a half-angle of $15^{\circ}$. The wedge-shaped deflector is plotted in Fig. 3, showing its placement on the nozzle.

\section{Computational Method}

Wind, an unsteady Reynolds-Averaged Navier-Stokes (RANS) solver was used with the Shear-Stress Turbulence (SST) turbulence model to predict the flow field for an asymmetric dual-stream jet. See Ref. 23 for more details on the flow solver and turbulence model. Structured grids were generated using Gridgen software by Pointwise Inc. The asymmetry created by the external wedge was captured using a three-dimensional grid. $6.3 \times 10^{6}$ grid points and eight blocks were used, shown in Fig. 1. Blocks 5 and 6 are above and behind the wedge, respectively. Block 6 extends from the wedge sidewall azimuthally around the computational domain $180^{\circ}$. The concentration of points that are very finely packed, necessitated by the viscous sublayer, is greater on the side near the wedge, giving the grid cross-section a spiral-like shape as it fans open. The flow field is computed from $\phi=0^{\circ}$ to $180^{\circ}$, and the solution is reflected about the plane of symmetry of the wedge, defined by the vertical axis (y-axis) and the nozzle centerline (x-axis). The computational domain spanned $30 D_{f}$ downstream of the plug tip, and $15 D_{f}$ radially outward from the jet centerline.

Grid sequencing was used to obtain faster convergence. The first grid used $1 / 4$ of the total grid points and the second grid used $1 / 2$ of the total grid points. In each step, a finer grid is used along with the solution from the previous grid as the initial guess. The multi-gridding showed mesh independence for the nozzle performance calculation, since the result was the same on both the medium and the fine grids. For both of the axisymmetric grids and for the asymmetric grid, a $y+$ value of 3 , corresponding to a distance of 0.0003 inches from the wall, was used to ensure accurate resolution of the boundary layers. The grid used for the static baseline jet was composed of 89328 grid points and six zones.

A jet with realistic exhaust conditions, simulating forward flight was tested. The jet was composed of cold air, to match conditions similar to prior experiments at UC Irvine. The secondary-to-primary velocity ratio was 0.7 , representative of the velocity ratio of turbofan exhaust. The free-stream Mach number used to simulate takeoff conditions was 0.2 . This free-stream condition is the same as that in recent NASA Langley ${ }^{12}$ wind tunnel tests which measured acoustic emissions with airfoil-shaped vanes on BPR 5 and BPR 8 nozzles in forward flight. 


\section{Results}

In the paragraphs that follow, the computational results are reported.

Figure 4 shows the kinetic energy distributions for the baseline jet and wedge deflector in forward flight. The baseline jet has a peak value of 0.011. The wedge decreases the value beneath the jet centerplane as shown in Fig. 6 . to a peak value of 0.00967 , a reduction of about ten percent. The values are also listed in Table 2. On the upper side the peak value is increased to 0.0827 , behind the wedge, where the primary stream is exposed to the ambient fluid. The reduction in turbulent kinetic energy on the side of the jet opposite the wedge should correspond to a reduction in far-field emissions in the direction opposite the wedge.

Figure 5 shows the mean velocity isocontours. In Fig. $5 \mathrm{~b}$ the wake due to the wedge is observed on the $x y$-plane. The pear-shaped cross-sectional velocity contours near the end of the potential core show that there is a reduction in the radial gradient of mean velocity due to the thickening of the low speed fluid underneath the jet. Pear-shaped contours were also observed in a previous computational study, by Georgiadis and Papamoschou ${ }^{13}$, and also in experimental studies ${ }^{2-4}$. Note the reduction in potential core length, listed in Table 2 . The reduction in potential core length is important because it corresponds to a reduction in the volume of the dominant turbulent mixing noise source. The end of the potential core, $x_{p}$ is defined where $\bar{u}_{\max }(x, y, 0)$ is $90 \%$ of the primary jet exit velocity.

Figure 7 shows the computationally determined tangent flow lines over the side of the wedge. There is very strong agreement between the computational and experimental surface flow visualizations, although the jet exhaust conditions are different. In the experiment, the conditions are static and low Mach number. The pattern provides guidance for designing an aerodynamically efficient wedge or flaps that would ideally be deployed during takeoff and retracted during cruise. Ideally, the wedge would form a long wake region in forward flight, producing minimal thrust loss.

The nozzle performance was calculated following the same procedure as Refs. 24-25, using the discharge coefficient to include the effect of the wedge on the mass-flow rate,

$$
C_{D}=\frac{\dot{m}}{\dot{m}_{\text {ideal }}} \text {. }
$$

The thrust coefficient is

$$
C_{f g}=\frac{F_{\text {press. }}+F_{\text {visc. }}+F_{f l u x}}{\left.F_{f l u x}\right|_{i d e a l}} .
$$

The product of the two coefficients $C_{f g} \cdot C_{D}$ is used to compare the actual performance of a nozzle to what could be achieved ideally. The calculated value for $C_{f g} \cdot C_{D}$ of $1.1 \%$ was the same as the value that was calculated for the thrust loss:

$$
\text { Thrust Loss }=\frac{F_{\text {Baseline }}-F_{\text {wedge }}}{F_{\text {Baseline }}} \times 100 \% \text {. }
$$

\section{Conclusions}

A computational investigation was conducted on the effect of wedge-shaped noise suppressors on the flow-field of a high-bypass-ratio nozzle in forward flight. A scaled down version of the GRC '5BB' nozzle was used to match the nozzle used in experimental studies. For the asymmetric jet in forward flight, with an external wedge, the peak turbulent kinetic energy beneath the jet centerplane and the potential core length are reduced when compared to the baseline values, suggesting the potential of the wedge to reduce noise toward the ground in forward flight. The nozzle performance was estimated to be $1.1 \%$ for the jet at takeoff conditions.

\section{Acknowledgments}

The first author would like to express her gratitude for the NASA Graduate Student Researchers Program (GSRP) fellowship that supported this research effort. 


\section{References}

${ }^{1}$ Papamoschou, D., "New Method for Jet Noise Suppression in Turbofan Engines," AIAA Journal, Vol. 42, No.11, 2004, pp. 2245-2253.

${ }^{2}$ Papamoschou, D., "Fan Flow Deflection in Simulated Turbofan Exhaust," AIAA Journal, Vol. 44, No.12, 2006, pp. 3088-3097.

${ }^{3}$ Shupe, R.S., Zaman, K.B.M.Q., Papamoschou, D., "Effect of Wedge-Shaped Deflector on Flow Fields of Dual-Stream Jets," AIAA Paper No. 3659, presented at the $13^{\text {th }}$ annual AIAA/CEAS Aeroacoustics Conference, May 2007, Rome, Italy.

${ }^{4}$ Shupe, R.S., Noise Reduction and Flow Characteristics in Asymmetric Dual-Stream Jets, Master's Thesis, University of California, Irvine, June 2007, Irvine, CA.

${ }^{5}$ Papamoschou, D. and Nishi, K.A., "Jet Noise Suppression with Fan Flow Deflectors in Realistic-Shaped Nozzle," AIAA Paper No. 0993, presented at the $43^{\text {rd }}$ annual AIAA Aerospace Sciences Meeting and Exhibit, January 2005, Reno, NV.

${ }^{6}$ Papamoschou, D. and Shupe, R.S., "Effect of Nozzle Geometry on Jet Noise Reduction using Fan Flow Deflectors," AIAA Paper No. 2707, presented at the $12^{\text {th }}$ annual AIAA/CEAS Aeroacoustics Conference, May 2006, Boston, MA.

${ }^{7}$ Papamoschou, D., "Parametric Study of Fan Flow Deflectors for Jet Noise Suppression," AIAA Paper No. 2890, presented at the $11^{\text {th }}$ annual AIAA/CEAS Aeroacoustics Conference, May 2005, Monterey, CA.

${ }^{8}$ Papamoschou, D., Vu, A., and Johnson, A., “Aerodynamics of Wedge-Shaped Deflectors for Jet Noise Reduction," AIAA

Paper No. 3655, presented at the $24^{\text {th }}$ AIAA Applied Aerodynamics Conference, June 2006, San Francisco, CA.

'Zaman, K.B.M.Q. and Papamoschou, D. "Effect of a Wedge on Coannular Jet Noise," AIAA Paper No. 0007, presented at the $44^{\text {th }}$ AIAA Aerospace Sciences Meeting, January 2006, Reno, NV.

${ }^{10}$ Zaman, K.B.M.Q., Bridges, J. E., and Papamoschou, D., "Offset stream technology comparison of results from experiments conducted at UCI and GRC," AIAA Paper No. 0438, presented at the $45^{\text {th }}$ annual AIAA Aerospace Sciences Meeting, January 2007, Reno, NV.

${ }^{11}$ Brown, C., Bridges, J. and Henderson, B., "Offset Stream Technology Test - Summary of Results", 13" AIAA/CEAS Aeroacoustics Conference, Rome, Italy, May 21-23, 2007.

${ }^{12}$ Henderson, B., Norum, T. and Bridges, J. E., "An MDOE Assessment of Nozzle Vanes for High Bypass Ratio Jet Noise Reduction," AIAA Paper 2006-2543, presented at the $12^{\text {th }}$ AIAA/CEAS Aeroacoustics Conference, Cambridge, MA, May 8-10, 2006.

${ }^{13}$ Papamoschou, D., "Mean Flow and Acoustics of Dual-Stream Jets," AIAA Paper 0004, presented at the 42 $2^{\text {nd }}$ AIAA Aerospace Sciences Meeting, January 2004, Reno, NV.

${ }^{14}$ K.B.M.Q. Zaman, "Spreading Characteristics of Compressible Jets," Journal of Fluid Mechanics, vol. 383, pp. 197-228, 1999.

${ }^{15}$ Murakami, E. and Papamoschou, D., "Mean Flow Development in Dual-Stream Jets," AIAA Journal, Vol.40, No.6, 2002, pp.1131-1138.

${ }^{16}$ Zaman, K.B.M.Q., "Effect of Initial Condition on Subsonic Jet Noise,” AIAA Journal, Vol. 23, No.9, 1984, pp. 1370-1373.

${ }^{17}$ Birch, S.F., Khritov, K.M., Maslov, V.P., Mironov, A.K., and Secundov, A.N., "An Experimental Study of Flow Asymmetry in Co-axial Jets," AIAA Paper 2845, presented at the $11^{\text {th }}$ AIAA/CEAS Aeroacoustics Conference, May 2005, Monterey, CA.

${ }^{18}$ Birch, S.F., Lyubimov, D.A., Buchshtab, P.A., Secundov, A.N., and Yakubovsky, K. Y., "Jet-Pylon Interaction Effects," AIAA Paper No. 3082, $11^{\text {th }}$ annual AIAA/CEAS Aeroacoustics Conference, May 2005, Monterey, CA.

${ }^{19}$ Mihăescu, M., Gutmark, E., and Martens, S., "Computational Aeroacoustics of a Separate Flow Exhaust System with Eccentric Inner Nozzle," AIAA Paper No. 0013, presented at the $45^{\text {th }}$ annual AIAA Aerospace Sciences Meeting, January 2006, Reno, NV.

${ }^{20}$ Birch, S.F., "A Review of Axisymmetric Jet Flow Data For Noise Applications," AIAA Paper 2602, presented at the $12^{\text {th }}$ AIAA/CEAS Aeroacoustics Conference, May 2006, Cambridge, MA.

${ }^{21}$ Georgiadis, N.J. and Papamoschou, D., "Computational Investigations of High-Speed Dual-Stream Jets," AIAA Paper No. 3311, presented at the $9^{\text {th }}$ annual AIAA/CEAS Aeroacoustics Conference, May 2003, Hilton Head, South Carolina.

${ }^{22}$ Georgiadis, N.J. and Papamoschou, D., "Computations of Dual-Stream Jets with Eccentric and Coaxial Bypass Streams," AIAA Paper No. 2981, presented at the $10^{\text {th }}$ annual AIAA/CEAS Aeroacoustics Conference, May 2004, Manchester, UK.

${ }^{23}$ Georgiadis, N.J. and DeBonis, J.R., "Navier-Stokes Analysis Methods for Turbulent Jet Flows with Application to Aircraft Exhaust Nozzles," Progress in Aerospace Sciences, Vol.42, 2006, pp.377-418.

${ }^{24}$ Dippold, V., Foster, F., and Wiese, M., "Computational Analyses of Offset Stream Nozzles for Noise Reduction," AIAA Paper No. 3589, presented at the $13^{\text {th }}$ annual AIAA/CEAS Aeroacoustics Conference, May 2007, Rome, Italy.

${ }^{25}$ DeBonis, J.R., "RANS Analyses of Turbofan Nozzles with Wedge Deflectors for Noise Reduction," AIAA Paper No. 0041, presented at the $46^{\text {th }}$ annual AIAA Aerospace Sciences Meeting, January 2008, Reno, NV.

${ }^{26}$ Birch, S.F., Lyubimov, D.A., Buchshtab, P.A., Secundov, A.N., and Yakubovsky, K. Y., "A RANS based Jet Noise Prediction Procedure," AIAA Paper No. 3589, presented at the $13^{\text {th }}$ annual AIAA/CEAS Aeroacoustics Conference, May 2007 , Rome, Italy. 
Table 1 Nozzle Exit Conditions

\begin{tabular}{lcc}
\hline Quantity & Primary & Secondary \\
\hline \hline Nozzle diameter $(\mathrm{mm})$ & 26.29 & 53.27 \\
Plug diameter $(\mathrm{mm})$ & 18.81 & - \\
Lip thickness $(\mathrm{mm})$ & 0.61 & - \\
Protrusion $(\mathrm{mm})$ & 23.16 & - \\
\hline \hline Velocity $(\mathrm{m} / \mathrm{s})$ & 260 & 180 \\
Mach number & 0.80 & 0.54 \\
Bypass ratio & - & 2.55 \\
\hline
\end{tabular}

Table 2 Flow Field Parameters

\begin{tabular}{lccc}
\hline Nozzle Configuration & $\begin{array}{c}\text { Peak } k / U_{p}^{2} \\
\text { Below }\end{array}$ & $\begin{array}{c}\text { Peak } k / U_{p}^{2} \\
\text { Above }\end{array}$ & $x_{p} / D_{f}$ \\
\hline \hline W1 CFD & 0.00967 & 0.0827 & 7.82 \\
Baseline CFD & 0.0110 & 0.0110 & 8.28 \\
\hline
\end{tabular}



Figure 1. Computational grid for the wedge configuration, showing blocks 4 and 5 , above and behind the wedge, respectively. Block 6 wraps around azimuthally from the side of the wedge, as shown in the next figure. 

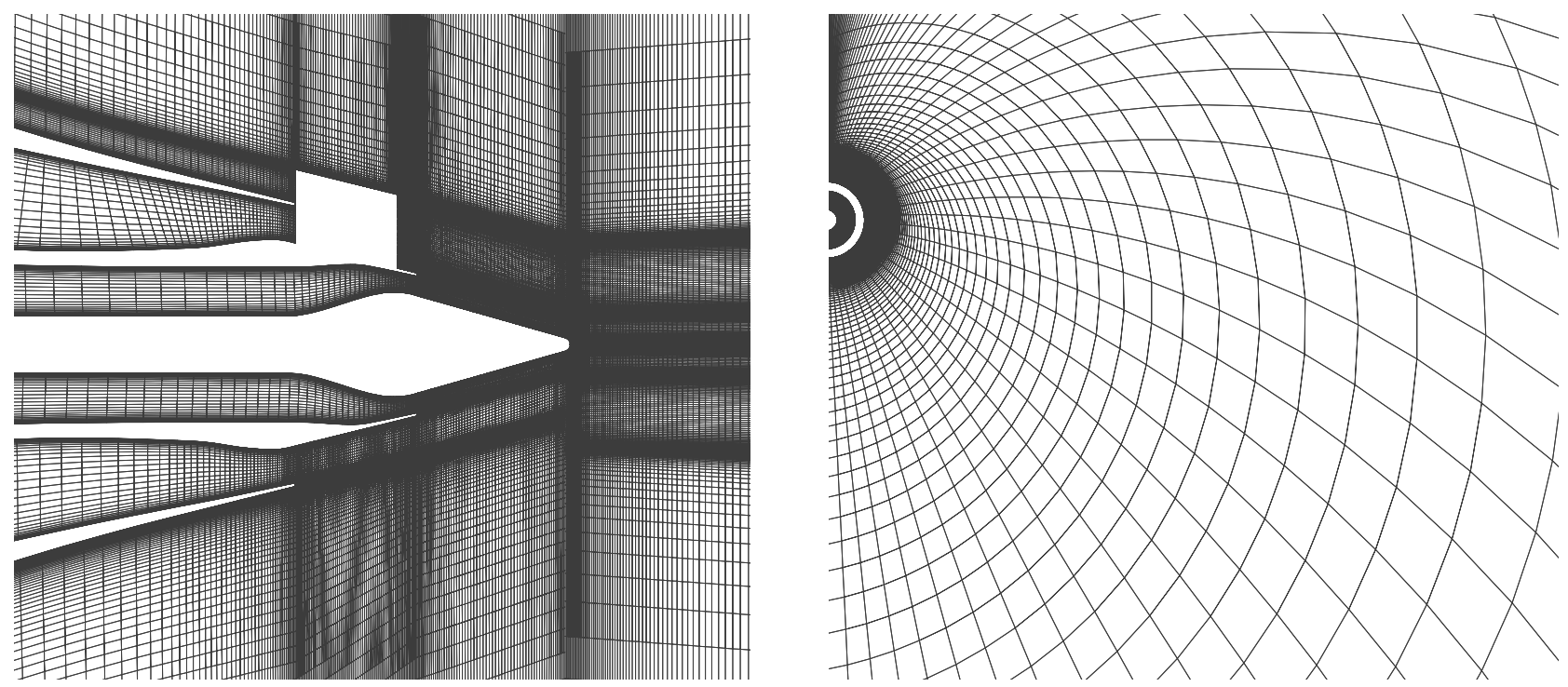

Figure 2. Structured grid near wedge in a) $x y$-plane b) $y z$-plane $x / D_{f}=0$ at the fan exit.


a)

b)

Figure 3. Radial coordinates for the '5BB' nozzle with external wedge a) side view b) end view. The wedge half angle is $\alpha=15^{\circ}$ and the base width is $10.4 \mathrm{~mm}$. 



a) BASE
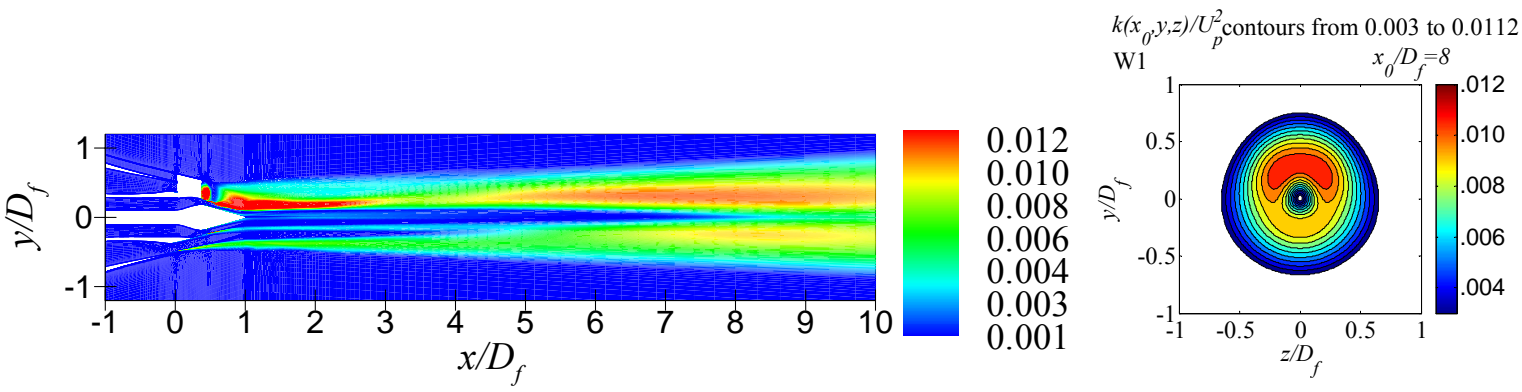

b) WEDGE

Figure 4. $k(x, y, 0) / U_{p}{ }^{2}$ distributions for the a) baseline jet b) and external wedge configurations in forward flight.

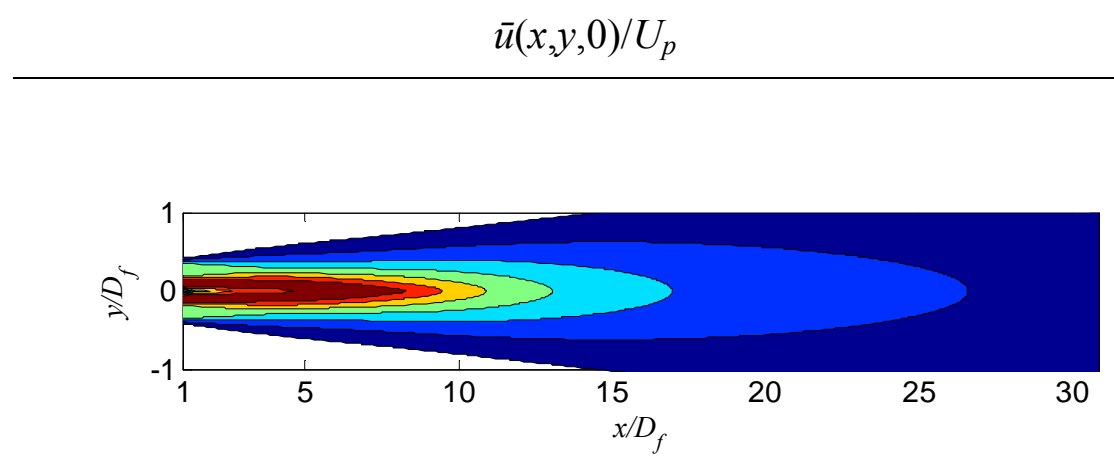

a) BASE
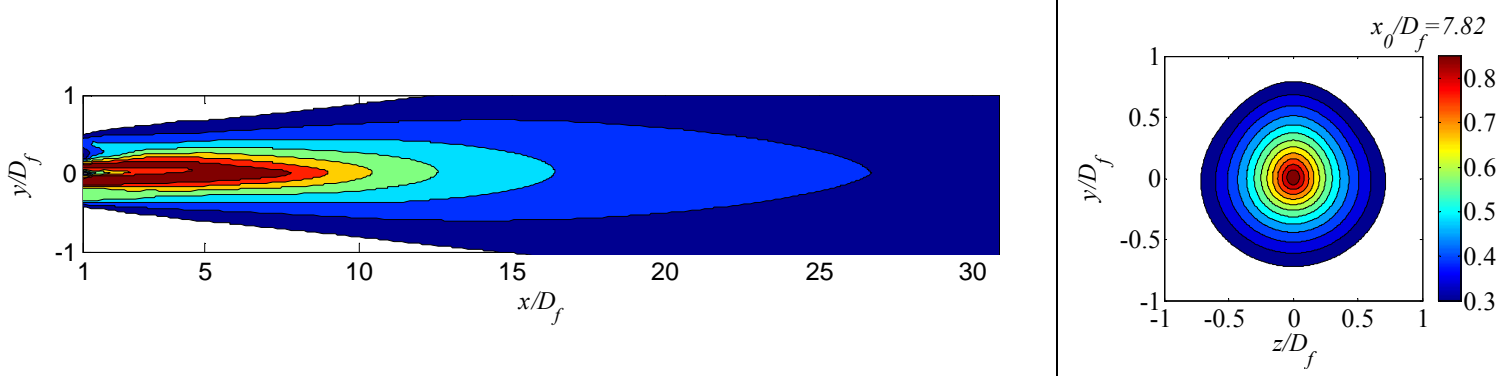

\section{b) WEDGE}

Figure 5. Mean velocity isocontours from 0.2 to 0.9 for the a) baseline jet $b$ ) and external wedge at takeoff conditions. 


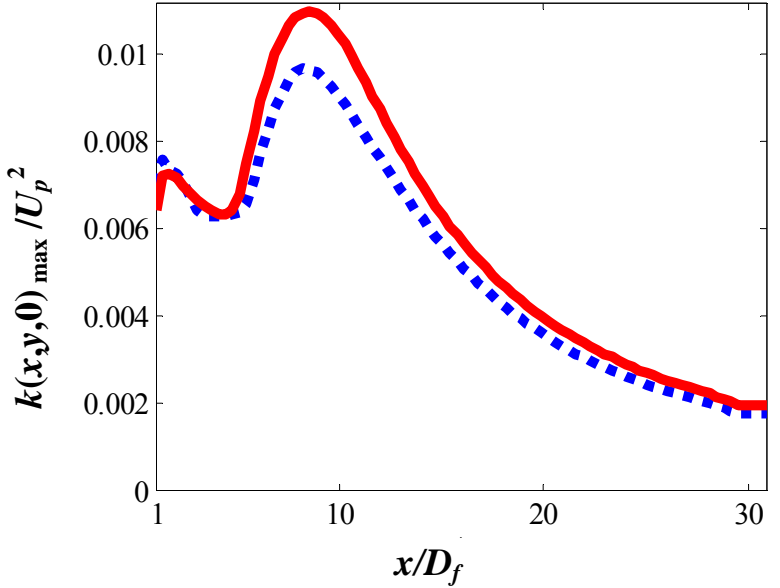

a)

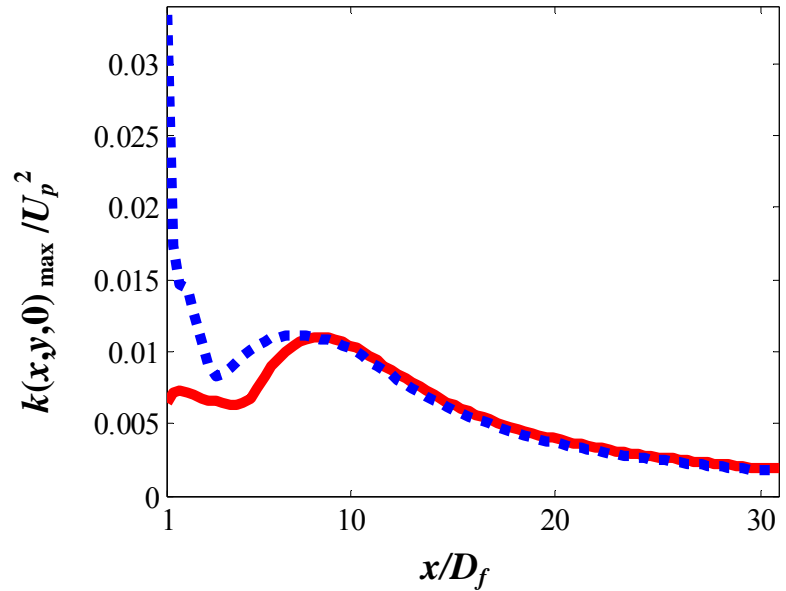

b)

Figure 6. Axial distributions of maximum turbulent kinetic energy a) below and b) above jet centerplane. Baseline jet — and asymmetric jet (external wedge) - - - values.

a)

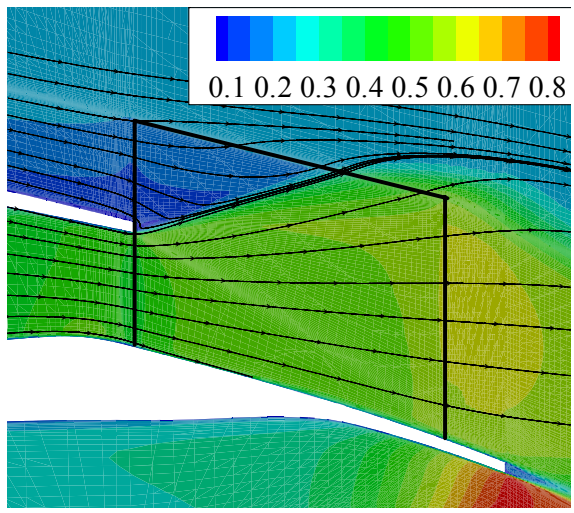

b)

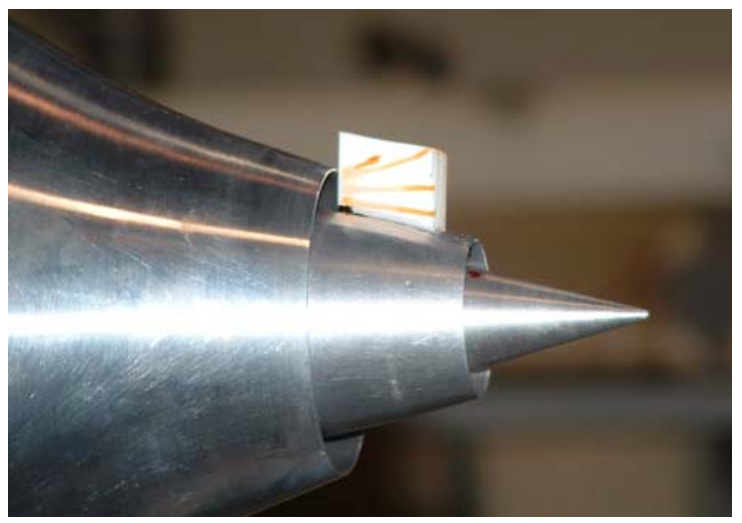

Figure 7. Computational flow field showing tangent lines to mean velocity along wedge sidewall overlaid on Mach number isocontours. $M_{p}=\mathbf{0 . 8 0}, M_{s}=0.54, M_{a}=0.2$. b) Surface flow visualization using watercolor paint $M_{p}=0.18, M_{s}=0.13, M_{a}=0$. 